\title{
OS ENSINOS PÚBLICO E PRIVADO NO BRASIL E A INCIDÊNCIA DE SOBRE-EDUCAÇÃO NO MERCADO DE TRABALHO
}

\author{
Mauricio Reis *
}

\begin{abstract}
Resumo
A baixa qualidade da educação costuma ser apontada como um dos fatores responsáveis pela incidência de sobre-educação, pois trabalhadores com determinado nível educacional não estariam capacitados para exercer as atividades compatíveis com os anos de estudo que completaram. O objetivo desse artigo é investigar a relação entre a rede de ensino e a probabilidade de sobre-educação no Brasil, explorando as diferenças de qualidade entre instituições públicas e privadas. De acordo com os resultados, entre os indivíduos com ensino médio, os egressos de escolas públicas tem maior probabilidade de serem sobre-educados, enquanto para o ensino superior é verificado o contrário.
\end{abstract}

Palavras-chave: ensino público, ensino privado, sobre-educação.

\begin{abstract}
Overeducation refers to the extent to which workers acquired education levels in excess of that required by their jobs. Low educational level is pointed out as a determinant for the incidence of overeducation, which is usually associated with negative labor market outcomes. According to this argument, poorly educated workers are only qualified for jobs that require less years of schooling than they obtained. This paper aims to investigate the relationship between the probability of overeducation and the type of educational system (public or private education, which have quite different quality levels in Brazil). Estimates show that workers with secondary education who completed their study in public schools are more likely to be overeducated than those who completed their secondary education in private schools, which usually have better quality than the former ones. Among workers with a bachelor's degree, those who completed their programs in public institutions, which usually have better quality than private ones for higher education, are less likely to be overeducated.
\end{abstract}

Keywords: public education, private education, over-education.

JEL classification: I21, J24

DOI: http://dx.doi .org/10.11606/1980-5330/ea 156324

\footnotetext{
* Instituto de Pesquisa Economica Aplicada. mauricio.reis@ipea.gov.br
} 


\section{Introdução}

Cerca de 30\% dos trabalhadores no Brasil apresentam um nível de escolaridade superior ao considerado necessário para o desempenho adequado das atividades nas suas ocupações. ${ }^{1}$

Esses trabalhadores, classificados na literatura econômica como sobre-edu-

cados, estão sujeitos, normalmente, a uma série de penalidades. Os anos adicionais de escolaridade, além dos que seriam necessários na ocupação, não parecem ser remunerados da mesma forma que os anos de escolaridade correspondentes às necessidades da ocupação. Evidências nesse sentido podem ser encontradas mesmo controlando para características individuais não observadas invariantes no tempo (Bauer (2002), Korpi \& Tåhlin (2009), Tsai (2010), mostram resultados para países desenvolvidos; enquanto Reis (2017) e Marioni (2018) apresentam evidências para o Brasil). Os resultados também mostram que os trabalhadores sobre-educados são mais propensos a apresentarem insatisfação com o emprego (Verhofstadt et al. 2007 e Allen \& Van der Velden 2001), exibindo também uma taxa de rotatividade mais elevada (Sicherman 1991).

Uma das razões apontadas para a incidência de sobre-educação nos países em desenvolvimento é a baixa qualidade educacional (Mehta et al. 2011). De acordo com esse argumento, os trabalhadores com determinado nível de escolaridade não seriam capacitados para exercer atividades compatíveis com o número de anos de estudo que completaram. Pela baixa qualidade da escolaridade adquirida por esses trabalhadores, as ocupações mais adequadas para as suas qualificações seriam aquelas com menores exigências em termos de anos de estudo. ${ }^{2}$

A qualidade da educação no Brasil pode ser considerada, em geral, muito baixa. No caso da educação básica, isso pode ser ilustrado, por exemplo, pelo desempenho muito ruim dos alunos brasileiros em testes padronizados internacionais, como o PISA - Programme for International Student Assessment. Em 2015, o desempenho do Brasil no PISA foi um dos piores entre cerca de 80 países avaliados pela OCDE - Organização para Cooperação e Desenvolvimento Econômico. Diferenças acentuadas de desempenho, porém, são encontradas entre os alunos de instituições públicas e privadas no Brasil. Para os alunos do nível básico, os resultados mostram um desempenho muito pior para os matriculados em instituições públicas do que para os alunos de instituições privadas (Terra et al. 2012, com base no SAEB - Sistema de Avaliação da Educação Básica) Já no caso da educação em nível superior, ocorre o inverso. Os alunos de instituições públicas apresentam, em média, resultados bem melhores no ENADE (Exame Nacional de Desempenho dos Estudantes), prova padronizada para avaliação dos cursos de nível superior, do que os alunos

\footnotetext{
${ }^{1}$ Dados da PNAD contínua referentes ao segundo trimestre de 2016, e usando informações da Classificação Brasileira de Ocupações - CBO (2010) para computar a escolaridade necessária em cada ocupação. De acordo com Quintini (2011), a porcentagem de trabalhadores em situação semelhante nos países da OCDE (Organização para a Cooperação e o Desenvolvimento Econômico) varia entre $10 \%$ e $35 \%$.

${ }^{2}$ Robst (1995) apresenta evidências da relação entre a qualidade da educação e a probabilidade de sobre-educação ao mostrar que trabalhadores que completaram o curso superior em faculdades piores são mais propensos a terem empregos que não exigem esse nível educacional nos Estados Unidos.
} 
de instituições privadas (Organização para a Cooperação e Desenvolvimento Econômico - OCDE 2013). ${ }^{3}$

A baixa qualidade do ensino público de nível básico pode fazer com que uma proporção elevada dos alunos com até o ensino médio concluído que realizaram os seus estudos nesse tipo de instituição não estejam capacitados para exercer tarefas condizentes com o nível de escolaridade alcançado. Esses trabalhadores, então, estariam mais propensos a terem uma ocupação onde seriam classificados como sobre-educados do que os indivíduos com escolaridade semelhante egressos de instituições privadas. Espera-se também que os indivíduos que frequentaram instituições privadas de nível superior sejam mais propensos a terem uma ocupação que exige escolaridade mais baixa do que aqueles que frequentaram instituições públicas de nível superior, que geralmente oferecem um ensino de melhor qualidade que as privadas.

O objetivo deste artigo é examinar como o fato de um indivíduo ter estudado em uma instituição pública ou privada de ensino está relacionado com a probabilidade de que seja um trabalhador sobre-educado no Brasil. Como esses dois tipos de instituições têm características muito diferentes na educação básica e na educação superior, a análise é feita separadamente para cada um desses segmentos educacionais. Para essa análise, são usados dados do suplemento sobre educação da PNAD contínua (Pesquisa Nacional por Amostra de Domicílios contínua) do segundo trimestre de 2016, e da CBO (Classificação Brasileira de Ocupações) de 2010 para computar a escolaridade necessária em cada ocupação.

De acordo com os resultados, entre os indivíduos com o ensino médio completo, os egressos de escolas da rede pública têm maior probabilidade de sobre-educação em comparação com os que saíram de escolas privadas. $\mathrm{O}$ diferencial estimado é de 14,2 pontos percentuais. Para os que completaram um curso superior, os resultados mostram que aqueles que concluíram a formação em uma instituição pública possuem uma probabilidade menor em 4,5 pontos percentuais de terem um emprego que não exige formação superior. Portanto, o tipo de instituição de ensino com pior qualidade média se mostra associado a uma probabilidade relativamente maior de sobre-educação.

O artigo está estruturado em seis seções, além desta introdução. A seção 2 descreve brevemente como a presença de desajustes entre a escolaridade do trabalhador e exigências da sua ocupação está relacionada com diferentes abordagens teóricas. Na seção 3, é feita uma descrição dos dados do suplemento da PNAD contínua e da Classificação Brasileira de Ocupações - CBO (2010) utilizados na análise. A seção 4 apresenta estatísticas descritivas comparando os trabalhadores egressos de instituições públicas com os egressos de instituições privadas. Na seção 5, são apresentados os métodos empíricos utilizados, e na seção 6 são mostrados os resultados estimados relacionando a probabilidade de sobre-educação com o tipo de instituição (pública ou privada) onde o trabalhador concluiu os seus estudos. As principais conclusões do artigo são apresentadas na seção 7 .

\footnotetext{
${ }^{3}$ Os resultados do SAEB/Prova Brasil de 2011 para alunos do $3^{\circ}$ ano do ensino médio mostram que as notas em português para as escolas privadas são $20 \%$ maiores que as notas para as escolas públicas, em média (INEP 2011). Em matemática, a média para os alunos das escolas privadas é $25 \%$ maior. De acordo com os resultados do ENAD de 2008, $90 \%$ dos alunos com desempenho máximo, igual a 5 em uma escala que varia de 1 até 5 , são de instituições públicas de ensino superior, enquanto $75 \%$ dos alunos com desempenho igual a 1 ou 2 são de instituições privadas (Organização para a Cooperação e Desenvolvimento Econômico - OCDE 2013).
} 


\section{As principais abordagens teóricas relacionadas à sobre-educação}

A incidência e as implicações para o mercado de trabalho de desequilíbrios entre o nível educacional dos trabalhadores e a necessidade das firmas têm sido analisadas na literatura econômica a partir de diferentes abordagens. Nesta seção, são apresentados brevemente os principais modelos teóricos utilizados para investigar essa questão. ${ }^{4}$ Além disso, pretende-se discutir de que maneira essas abordagens teóricas estão relacionadas com a análise empírica proposta neste artigo.

De acordo com a teoria do capital humano, os trabalhadores são remunerados conforme a sua produtividade marginal, que por sua vez, é determinada pelo nível de qualificação acumulado, seja através da educação formal ou do treinamento no emprego. Para que a incidência de sobre-educação seja conciliada com a teoria do capital humano, deve ser uma situação apenas temporária, de desequilíbrio de curto-prazo. Além disso, na teoria do capital humano, a representação dos rendimentos como função apenas da escolaridade adquirida implica em igualdade dos coeficientes associados com a escolaridade requerida na ocupação e com o excesso de educação na equação de rendimentos. Esses coeficientes, por sua vez, devem ser iguais ao negativo do coeficiente associado ao déficit de escolaridade. Testes para essa hipótese conjunta, porém, são invariavelmente rejeitados segundo Leuven \& Oosterbeek (2011).

Para conciliar a presença de sobre-educação com a teoria do capital humano, McGuinness (2006) propõe uma versão modificada desse modelo. Nessa abordagem, os anos adicionais de estudo, além do nível exigido na ocupação, estariam desempenhando o papel de compensar deficiências na qualidade do capital humano adquirido pelos sobre-educados, além de déficits na acumulação de capital humano não formal, ou em outras variáveis não consideradas. Dessa forma, a pior qualidade do ensino levaria muitos trabalhadores a condição de sobre-educados, em empregos onde a exigência de anos de escolaridade é menor que o nível alcançado, embora a qualificação adquirida seja compatível com a necessidade do emprego.

Nos modelos de job competition (Thurow 1975), o único fator que determina os salários é a característica do emprego. Com uma oferta limitada de vagas, os trabalhadores competem por emprego usando a escolaridade, que tem o papel, nesses modelos, de reduzir os custos de treinamento das firmas com os trabalhadores contratados. Nesse caso, a escolaridade não tem influência sobre a produtividade ou sobre os salários, mas pode melhorar a posição do trabalhador na fila de contratações. Com isso, pode ocorrer um incentivo para o investimento acentuado em educação, levando a uma situação de sobreeducação. Nos modelos de job competition, tanto o excesso quanto o déficit educacional tem efeito nulo sobre os rendimentos. No entanto, os testes empíricos normalmente rejeitam essa hipótese (Leuven \& Oosterbeek 2011).

Os modelos de sinalização (Spence 1973) podem levar a uma situação semelhante a que é proposta no modelo de job competition. Supõe-se que os custos para adquirir educação sejam menores para os trabalhadores mais produtivos. Então, embora a educação também não tenha influência sobre a produtividade, os trabalhadores mais produtivos investem para adquirir mais

\footnotetext{
${ }^{4}$ Resumos sobre essa literatura podem ser encontrados em Hartog (2000), Groot \& Van Den Brink (2000), Sloane (2003), McGuinness (2006), Leuven \& Oosterbeek (2011)
} 
escolaridade e assim alcançarem melhores empregos, podendo gerar sobreeducação.

Os modelos de assignment (Sattinger 1993) podem ser considerados como uma situação intermediária entre a teoria do capital humano e os modelos de job competition e sinalização. Nesse caso, os salários dependem da interação entre trabalhadores heterogêneos e empregos, que também têm características heterogêneas. Aumentos na escolaridade elevam a produtividade de maneira geral, mas esse efeito pode ser maior ou menor dependendo do nível de complexidade dos empregos que são preenchidos. Nos modelos de assignment, ao contrário do modelo neoclássico padrão, representado pela teoria do capital humano, a disponibilidade e a qualidade dos empregos encontrados na economia também influenciam a produtividade e os rendimentos, que não estão restritos à escolaridade e à experiência no mercado de trabalho. Trabalhadores em empregos que exigem uma escolaridade menor que a alcançada por eles têm as suas capacidades produtivas limitadas, recebendo salários menores do que receberiam caso estivessem em uma ocupação adequada para a educação.

Desajustes entre a escolaridade dos trabalhadores e a necessidade das firmas podem ocorrer em equilíbrio nesses modelos de assignment pela maneira como os diferentes tipos de empregos e de trabalhadores estão distribuídos. Uma parcela de trabalhadores mais escolarizados que não encontra uma disponibilidade correspondente de empregos com maior complexidade no mercado de trabalho vai levar à presença de sobre-educação, de acordo com esse tipo de modelo.

A presença de uma proporção elevada de trabalhadores sobre-educados costuma ser associada com uma abundância de trabalhadores mais escolarizados. No Brasil, porém, são observados níveis elevados de sobre-educação, juntamente com uma escolaridade média da força de trabalho relativamente baixa. Situação semelhante é observada em outros países em desenvolvimento, o que é atribuído por Mehta et al. (2011) a baixa qualidade da educação. A incidência de sobre-educação no Brasil, dessa forma, estaria de acordo com a variante do modelo neoclássico padrão, citada por McGuinness (2006), em que os anos de estudo não são capazes de representar corretamente a qualificação dos trabalhadores. Pela baixa qualidade da educação adquirida, trabalhadores com determinado número de anos de estudo não estariam aptos a desempenhar as atividades nas ocupações com necessidades correspondentes aos anos de escolaridade que completaram.

Como destacado por Quintini (2011), os modelos de assignment tem se mostrado os mais consistentes com os fatos observados para a presença e os efeitos de desajustes entre a escolaridade dos trabalhadores e as necessidades das firmas. Esses modelos também devem ser importantes no caso brasileiro, em que a oferta de trabalhadores mais escolarizados seria excessiva em relação à disponibilidade de empregos de maior qualidade, associados a tecnologias mais modernas e que exigem trabalhadores mais qualificados. De acordo com Pauli et al. (2012), o Brasil experimentou uma situação desse tipo durante a década de noventa.

Embora os modelos de assignment possivelmente desempenhem um papel relevante para se entender questões relacionadas à sobre-educação no Brasil, a abordagem proposta nesse artigo está baseada na variante do modelo de capital humano que explora as implicações da pior qualidade da educação. Mesmo que instituições públicas e privadas sejam bastante heterogêneas, apresentando, cada uma delas, os mais diferentes graus de qualidade, em mé- 
dia, as escolas privadas de nível médio são bem superiores às escolas públicas, enquanto as instituições públicas de nível superior são bem melhores que as privadas. Pretende-se investigar em que medida essas deficiências na qualidade do ensino público de nível médio e do ensino superior privado desempenham um papel na alocação de trabalhadores em ocupações nas quais são classificados como sobre-educados.

\section{Dados}

A análise empírica neste artigo utiliza os dados do suplemento sobre educação da PNAD contínua referente ao segundo trimestre de 2016. Além das variáveis normalmente investigadas na PNAD contínua pelo IBGE (Instituto Brasileiro de Geografia e Estatística), esse suplemento contém perguntas sobre a rede de ensino anteriormente frequentada, assim como sobre cursos de educação profissional. Essas perguntas são feitas para todos os indivíduos com 5 anos ou mais de idade, independentemente do número da entrevista no domicílio. ${ }^{5}$ Para os indivíduos que já frequentaram a escola, a PNAD contínua pergunta sobre o grau e a última série ou semestre concluídos com aprovação. No suplemento, é perguntado também sobre a rede de ensino desse curso. Três opções são apresentadas para os entrevistados: i) somente na rede privada, ii) somente da rede pública, e iii) na rede privada e pública. São excluídos da análise empírica neste artigo os indivíduos que selecionaram essa última opção. ${ }^{6}$

Além do indicador da rede de ensino do curso onde cada indivíduo concluiu a escolaridade mais elevada, são utilizadas na análise informações individuais como idade, gênero, cor ou raça ${ }^{7}$ e região de residência, além do número de anos de estudos completados. ${ }^{8}$ Para cada indivíduo ocupado, a pesquisa oferece também os rendimentos mensais e por hora trabalhada, assim como a ocupação definida para o nível de 4 dígitos.

A Classificação Brasileira de Ocupações - CBO (2010) disponibiliza diversas informações sobre as características de cada ocupação definida para o nível de 4 dígitos. Para isso, cada ocupação é analisada por uma equipe de especialistas selecionados pelo Ministério do Trabalho em oficinas com duração de três dias, seguindo o método DACUM (Developing a Curriculum). Nos primeiros dois dias, comitês de 8 a 12 especialistas em cada ocupação elaboram descrições referentes a vários aspectos, entre os quais, a qualificação considerada necessária para o desempenho adequado de cada ocupação. No terceiro dia, essas descrições são validadas por outros comitês de trabalhadores.

Para cada ocupação na Classificação Brasileira de Ocupações - CBO (2010), portanto, é possível encontrar o nível de escolaridade requerido para o exercício dessa mesma ocupação, de acordo com a avaliação da equipe de especialistas. Na PNAD contínua as ocupações também são definidas para o nível de 4 dígitos. Associando cada ocupação na PNAD contínua com a ocupação correspondente na Classificação Brasileira de Ocupações - CBO (2010), a informação

\footnotetext{
${ }^{5} \mathrm{Na}$ PNAD contínua, cada domicílio é entrevistado por cinco trimestres consecutivos.

${ }^{6}$ Apenas $2 \%$ dos indivíduos frequentaram o curso mais elevado nas redes privada e pública.

${ }^{7}$ Os indivíduos são classificados no artigo como negros, nos quais são incluídos os pardos e os indígenas, ou brancos, onde também são incluídos os asiáticos.

${ }^{8}$ Indivíduos com pós-graduação, completa ou incompleta, são considerados juntamente com aqueles com graduação completa, pois a escolaridade requerida é definida, no máximo, para o ensino superior completo.
} 
sobre a escolaridade necessária na ocupação proveniente dessa última fonte pode ser imputada a cada indivíduo na PNAD contínua. Dessa maneira, um indivíduo empregado na PNAD contínua é classificado como sobre-educado neste artigo caso tenha completado um número de anos de estudo maior que o nível considerado necessário na sua ocupação. Caso contrário, esse indivíduo é classificado como adequadamente escolarizado ou subeducado.

A amostra principal é composta por indivíduos com idade entre 25 e 60 anos, ocupados na semana de referência da pesquisa. Legisladores e dirigentes do setor púbico, além de militares, para os quais não é definida a escolaridade requerida, assim como indivíduos sem informações sobre a ocupação, são excluídos da amostra. No total, cerca de 120.000 observações fazem parte da amostra principal. Apenas os indivíduos ocupados podem ser classificados como sobre-educados ou não. No entanto, pode existir uma seleção dos indivíduos ocupados em relação aos desempregados e inativos. Além disso, essa seleção pode estar associada com o tipo de instituição de ensino, com indivíduos provenientes de instituições de pior qualidade menos propensos a conseguirem emprego.

Para considerar um possível viés em razão dessa seleção, é utilizada também uma amostra mais ampla que incluí, além dos trabalhadores empregados, os desempregados e os que não estão participando do mercado de trabalho. São selecionados, nesse caso, todos os indivíduos com idade entre $25 \mathrm{e}$ 60 anos, excluídos apenas os ocupados como legisladores, dirigentes do setor púbico e militares, assim como os indivíduos que se declaram ocupados, mas não fornecem informações sobre a ocupação. Essa segunda amostra contém cerca de 180.000 observações.

\section{Análise descritiva}

A Tabela 1 apresenta as médias de algumas variáveis separadamente para egressos de instituições públicas e privadas. ${ }^{9}$ Essa tabela mostra que, em média, o total de trabalhadores egressos de instituições privadas recebe rendimentos superiores em mais de duas vezes quando comparados com o total de egressos de instituições públicas. Esses diferenciais são válidos tanto para os rendimentos mensais quanto para os rendimentos por hora trabalhada. Diferenças acentuadas também podem ser notadas em relação à escolaridade, pois enquanto os indivíduos que frequentaram a última série na rede privada de ensino têm, em média, 14 anos de escolaridade, e aqueles que frequentaram a rede pública apresentam média de 8,5 anos. Essa diferença na escolaridade média é importante para explicar esse enorme diferencial de rendimentos. A Tabela 1 também mostra que a proporção de mulheres é maior entre os egressos de instituições privadas, e que a proporção de negros é maior entre os que saíram de instituições públicas.

Entre os indivíduos que concluíram os estudos na rede pública, $28 \%$ são classificados como sobre-educados, sendo a média de anos de sobre-educação entre esses trabalhadores igual a 3,5 anos. Já entre os que frequentaram a rede privada de ensino, e que são mais escolarizados, a porcentagem de sobreeducados é igual a 33\%, com média de 4 anos de sobre-educação entre os indivíduos classificados dessa forma. A Tabela 1 mostra ainda que $80 \%$ dos

\footnotetext{
${ }^{9}$ As observações são ponderadas usando o peso de cada pessoa na amostra.
} 
Tabela 1: Estatísticas descritivas por rede de ensino do último ano de estudo concluído

\begin{tabular}{lcc}
\hline & $(\mathbf{1})$ & $(2)$ \\
\cline { 2 - 3 } & Rede pública & Rede privada \\
\hline Escolaridade & 8,56 & 14,07 \\
Idade & 40,74 & 39,44 \\
Mulher (\%) & 41,90 & 53,25 \\
Negro (\%) & 55,62 & 31,52 \\
Rendimento do trabalho principal (R\$) & $1.227,70$ & $2.839,24$ \\
Rendimento do trabalho principal & 7,59 & 17,87 \\
por hora (R\$) & 27,95 & 33,16 \\
Sobre-educação (\%) & 3,53 & 4,02 \\
Anos de sobre-educação (para & & \\
os sobre-educados) & \multicolumn{2}{|}{} \\
\hline & 101.254 & 19.647 \\
\hline Observações & 79,96 & 20,04 \\
Participação ponderada (\%)
\end{tabular}

Fonte: Suplemento sobre educação da PNAD contínua (2016.2).

trabalhadores ocupados na amostra saíram da rede pública, enquanto os demais vieram da rede privada de ensino. ${ }^{10}$ Considerando as participações desses dois grupos, a porcentagem total de sobre-educados é de $29 \%$. Esse valor é semelhante aos obtidos com outras bases de dados para o Brasil em períodos mais recentes. ${ }^{11}$

Esses resultados na Tabela 1, porém, escondem uma grande heterogeneidade entre trabalhadores com ensino superior e aqueles com até o ensino médio. Para descrever mais detalhadamente a diferença educacional entre as duas redes de ensino representadas na Tabela 1, a Figura 1 apresenta as distribuições dos trabalhadores provenientes de instituições públicas e privadas por ano completo de estudo. Entre os que frequentaram a rede pública, $40 \%$ completaram 11 anos de estudo (correspondente ao ensino médio completo), enquanto as porcentagens dos que completaram 4,8 (correspondente ao ensino fundamental completo) ou 15 anos (correspondente ao ensino superior completo) se situam em torno de $10 \%$. Situação bem diferente é verificada para os egressos de instituições privadas, pois $70 \%$ completaram o curso superior. Ainda nesse segundo grupo, 10\% completaram o ensino médio, enquanto um total de $15 \%$ completou pelo menos um ano do ensino superior (entre 12 e 14 anos de estudo), mas sem concluir o grau. Em ambos os grupos reportados na Figura 1, nota-se que as distribuições estão concentradas em anos correspondentes a graus completos.

Na Tabela 2, são apresentadas estatísticas descritivas para os dois grupos de escolaridade mais importantes, o formado por indivíduos com exatamente o ensino médio completo e o composto por indivíduos com curso superior completo. Entre os que completaram o ensino médio, $94 \%$ são egressos da rede pública (na coluna (1)). Esses trabalhadores têm rendimentos menores

\footnotetext{
${ }^{10}$ Foram excluídos os indivíduos que frequentaram a rede privada e a pública.

${ }^{11}$ Diaz \& M (2008) encontram uma taxa de sobre-educação de $17 \%$ usando dados do Censo de 2000, enquanto em Reis (2017) e Marioni (2018) 25\% dos trabalhadores são classificados como sobre-educados. Reis (2017) utiliza dados da PME (Pesquisa Mensal de Emprego) de 2004 até 2015 e da PNAD contínua entre 2012 e 2015, e Marioni (2018) usa informações da RAIS (Relação Anual de Informações Sociais) entre 2006 e 2013.
} 
Figura 1: Distribuição dos trabalhadores por escolaridade nas instituições

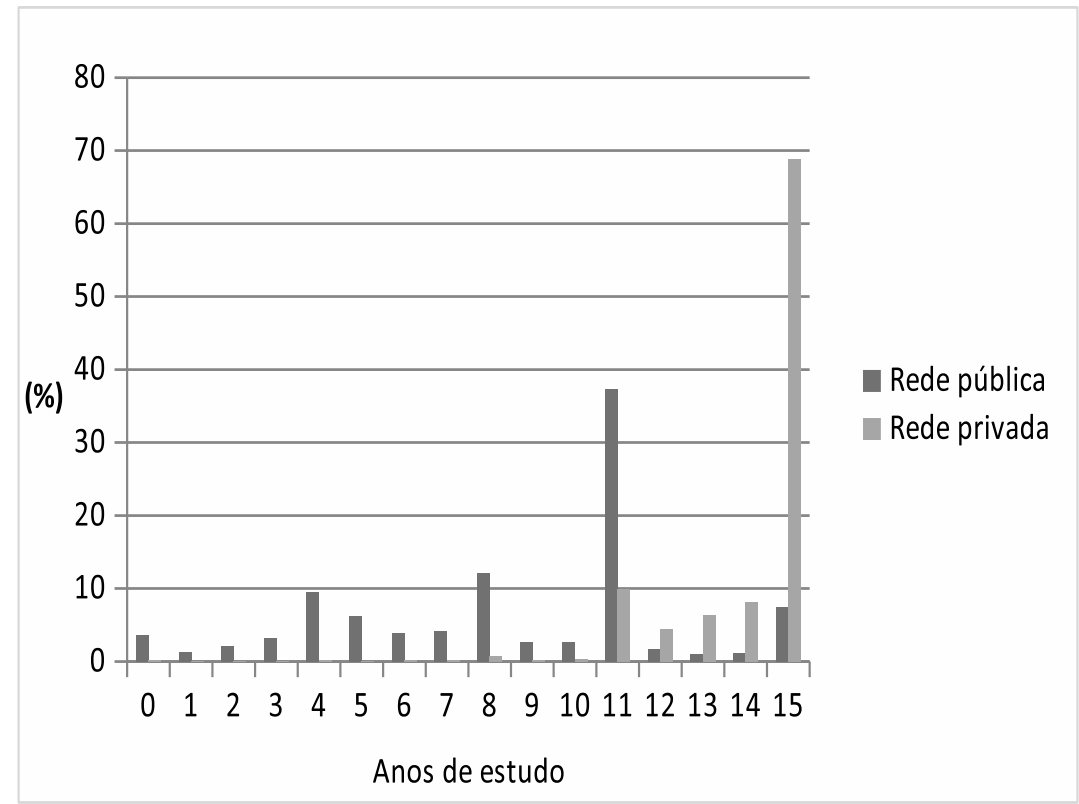

Fonte: Suplemento sobre educação da PNAD contínua (2016.2).

em cerca de $50 \%$ quando comparados aos indivíduos egressos de instituições privadas (na coluna (2)). Na coluna (1), os indivíduos são mais jovens, em média, e mulheres e negros têm participações maiores do que na coluna (2), o que contribui para que os rendimentos sejam menores para os egressos da rede pública. Mais de $42 \%$ dos indivíduos com 11 anos de estudos completados em instituições públicas são classificados como sobre-educados. Entre os indivíduos com a mesma escolaridade que frequentaram instituições privadas, $28 \%$ são sobre-educados, uma diferença de 14 pontos percentuais, portanto.

Entre os trabalhadores com curso superior completo, os diferenciais de rendimentos são bem menores e passam a favorecer os egressos de instituições públicas (na coluna (3)), que recebem $10 \%$ a mais que aqueles vindos de instituições privadas (na coluna (4)). Os negros apresentam uma participação maior na coluna (3) em relação a (4), mas a média de idade e a proporção de mulheres são semelhantes entre esses dois grupos. Entre os indivíduos que completaram o curso superior em uma instituição pública, $23 \%$ têm ocupações que não exigem esse nível de escolaridade. Já entre os que completaram o curso superior na rede privada, a porcentagem de sobre-educados é um pouco maior, $28 \%$. A coluna (4) da Tabela 2 mostra também que $70 \%$ dos trabalhadores na amostra que completaram um curso superior o fizeram em uma instituição privada. Assim como no caso dos indivíduos com 11 anos de estudos, as evidências nas colunas (3) e (4) estão de acordo com o argumento proposto no artigo de que, condicionando na escolaridade, a incidência de sobre-educação é maior para os egressos da rede de ensino na qual a qualidade média é considerada mais baixa. 
Tabela 2: Estatísticas descritivas por rede de ensino para trabalhadores com 11 e 15 anos de estudo

\begin{tabular}{|c|c|c|}
\hline & (1) & $(2)$ \\
\hline & \multicolumn{2}{|c|}{ Amostra: Escolaridade $=11$ anos } \\
\hline & Escola pública & Escola particular \\
\hline Idade & 38,47 & 41,07 \\
\hline Mulher (\%) & 46,26 & 41,64 \\
\hline Negro (\%) & 52,13 & 41,70 \\
\hline $\begin{array}{l}\text { Rendimento do trabalho } \\
\text { principal }(\mathrm{R} \$)\end{array}$ & $1.201,15$ & $1.886,97$ \\
\hline $\begin{array}{l}\text { Rendimento do trabalho } \\
\text { principal por hora }(\mathrm{R} \$)\end{array}$ & 7,28 & 12,02 \\
\hline Sobre-educação (\%) & 42,56 & 28,54 \\
\hline $\begin{array}{l}\text { Anos de sobre-educação (para } \\
\text { os sobre-educados) }\end{array}$ & 3,81 & 4,08 \\
\hline Observações & 34.066 & 2.198 \\
\hline \multirow[t]{4}{*}{ Participação ponderada (\%) } & 93,72 & 6,28 \\
\hline & (3) & $(4)$ \\
\hline & \multicolumn{2}{|c|}{ Amostra: Escolaridade $=15$ anos } \\
\hline & Escola pública & Escola particular \\
\hline Idade & 40,56 & 39,42 \\
\hline Mulher (\%) & 57,72 & 56,39 \\
\hline Negro (\%) & 36,92 & 27,46 \\
\hline $\begin{array}{l}\text { Rendimento do trabalho } \\
\text { principal }(\mathrm{R} \$)\end{array}$ & $3.577,65$ & $3.263,85$ \\
\hline $\begin{array}{l}\text { Rendimento do trabalho } \\
\text { principal por hora }(\mathrm{R} \$)\end{array}$ & 22,60 & 20,59 \\
\hline Sobre-educação (\%) & 23,90 & 27,77 \\
\hline $\begin{array}{l}\text { Anos de sobre-educação (para } \\
\text { os sobre-educados) }\end{array}$ & 4,57 & 4,55 \\
\hline Observações & 7.280 & 13.171 \\
\hline Participação ponderada (\%) & 30,14 & 69,86 \\
\hline
\end{tabular}

\section{Métodos empíricos}

As evidências empíricas principais são baseadas em estimações para a probabilidade de um indivíduo ser classificado como sobre-educado em função de uma variável dummy que é igual a um caso esse indivíduo tenha completado os estudos na rede pública e igual a zero caso tenha completado na rede privada. As regressões são estimadas usando o modelo probit, como na equação abaixo:

$$
\operatorname{Prob}(y=1 \mid P u b, X)=\Phi\left(\beta_{0}+\beta_{1} P u b+\gamma X\right)
$$

em que $y=1$ caso o indivíduo seja sobre-educado, e $y=0$ caso contrário, $P u b$ é uma variável dummy igual a um para os egressos da rede pública e igual a zero para os egressos da rede privada, $X$ contém algumas caraterísticas individuais, e $\Phi$ representa a função distribuição acumulada da normal padrão. As variáveis incluídas em X são: anos completos de estudo, idade, idade ao qua- 
drado, uma dummy para as mulheres, uma dummy para os indivíduos negros, que inclui também os pardos, e dummies para a região de residência.

As regressões são estimadas separadamente para os egressos do ensino básico e do superior. No primeiro caso, $\beta_{1}>0$ indica que a probabilidade de sobre-educação é maior para os indivíduos que concluíram a educação no sistema público em relação aos que saíram de instituições privadas. No caso da educação superior, espera-se, de acordo com os argumentos baseados em diferenças de qualidade, que $\beta_{1}<0$. Ou seja, que os indivíduos que concluíram a educação superior em instituições públicas tenham menor probabilidade de sobre-educação que os egressos de instituições privadas.

Indivíduos desempregados e inativos não podem ser classificados em relação à sobre-educação, já que não possuem uma ocupação. Como a probabilidade de estar empregado pode depender da rede de ensino frequentada pela pessoa, é possível que a seleção amostral dos indivíduos entre os empregados influencie os resultados. Para levar em conta essa questão, é estimado um modelo probit com seleção amostral (Heckman 1979; Van de Ven \& Van Pragg 1981).

Essa análise é baseada no seguinte modelo:

$$
\begin{aligned}
& y_{1}=1\left[\beta_{0}+\beta_{1} P u b+\gamma X+u_{1}>0\right] \\
& y_{2}=1\left[\alpha_{0}+\alpha_{1} P u b+\delta Z+u_{2}>0\right]
\end{aligned}
$$

em que: $u_{1} \sim N(0,1), u_{2} \sim N(0,1)$, e $\operatorname{corr}\left(u_{1}, u_{2}\right)=\rho$.

A equação (2) se refere à probabilidade de sobre-educação, sendo válida apenas quando $y_{2}>0$, e não é observada caso contrário. A equação de seleção (3) se refere à probabilidade de o indivíduo estar ocupado. Apenas quando $y_{2}=1$, ou seja, o indivíduo está ocupado, ele pode ser classificado como sobreeducado ou não na equação (2).

Supondo que as probabilidades de sobre-educação e de emprego sejam determinadas por duas equações probit, os parâmetros desse modelo (os coeficientes das duas equações e a correlação entre $u_{1}$ e $u_{2}$ ) podem ser estimados pelo método de máxima verossimilhança. Se $\rho=0$, os dois modelos podem ser estimados separadamente, o que seria equivalente a estimar o modelo da equação (1) para a probabilidade de sobre-educação. As variáveis em $X$ são as mesmas incluídas na equação (1). Para identificar esse modelo, $Z$ inclui, além das variáveis em $X$, o número de crianças com 5 anos ou menos no domicílio, e a interação dessa variável com a dummy para as mulheres.

Outro exercício de robustez realizado consiste em estimar um modelo com três categorias para a condição no emprego: i) subeducado, ii) adequadamente educados, e iii) sobre-educado. Para isso, além dos sobre-educados, são definidos os subeducados como aqueles com escolaridade menor que a necessária na sua ocupação, e os adequadamente educados classificados como os indivíduos com escolaridade correspondente ao nível requerido na ocupação. Os subeducados normalmente têm rendimentos do trabalho menores que aqueles recebidos por indivíduos adequadamente educados em ocupações similares, porém, recebem mais que os trabalhadores adequadamente educados com o mesmo nível de escolaridade (Leuven \& Oosterbeek 2011) Ou seja, essa maior exigência na ocupação representa um ganho nos rendimentos. Para essa análise, não são incluídos na amostra os indivíduos com alguma instrução superior, pois a 
maioria desse grupo já tem o máximo de escolaridade que seria necessária nas ocupações disponibilizadas na CBO para o nível de 4 dígitos.

Usando como base o modelo logit multinomial, a probabilidade de um indivíduo pertencer ao grupo $j=1$ ou $j=3$ usando a categoria "adequadamente educado" $(j=2)$ como referência, pode ser representada por:

$$
P_{j}=\frac{\exp \left(\beta_{0 j}+\beta_{1 j} P u b+\gamma_{j} X_{j}\right)}{1+\exp \left(\beta_{01}+\beta_{11} P u b+\gamma_{1} X_{1}\right)+\exp \left(\beta_{03}+\beta_{13} P u b+\gamma_{3} X_{3}\right)}, j=1,3
$$

em que: $\beta_{1 j}$ é o coeficiente da variável $P u b$ para a categoria j e $\gamma_{j}$ é o vetor de coeficientes associados às variáveis contidas em $X$ para a categoria $j$.

A probabilidade de um indivíduo pertencer ao grupo de referência é:

$$
P_{j}=\frac{1}{1+\exp \left(\beta_{01}+\beta_{11} P u b+\gamma_{1} X_{1}\right)+\exp \left(\beta_{03}+\beta_{13} P u b+\gamma_{3} X_{3}\right)}
$$

A probabilidade de $j=3$, por exemplo, em relação ao grupo de referência, $j=2$, é chamada de razão de risco relativo, e pode ser representada como:

$$
\frac{P_{3}}{P_{2}}=\exp \left(\beta_{03}+\beta_{13} P u b+\gamma_{3} X_{3}\right)
$$

A razão de risco relativo correspondente à variável $P u b$ representa a mudança na probabilidade de sobre-educação em comparação com a probabilidade de o indivíduo estar adequadamente educado quando $P u b$ varia de 0 para 1. Essa razão é dada por $\exp \left(\beta_{13}\right)$.

Os coeficientes estimados para os grupos $j=1$ e $j=3$ devem ser interpretados em relação ao grupo de referência. Espera-se, portanto, que os egressos de escolas públicas de nível médio tenham não apenas uma probabilidade maior de sobre-educação como também uma probabilidade menor de subeducação em relação aos egressos de escolas particulares com o mesmo nível educacional. Embora os resultados com o modelo logit multinomial ofereçam evidências adicionais relacionadas com a hipótese que se pretende investigar neste artigo, esse tipo de modelo possui uma limitação importante. Supõe-se que a probabilidade de $j=2$ em relação a $j=1$ seja independente da alternativa $j=3$.

\section{Resultados}

\subsection{Resultados principais}

A Tabela 3 mostra os resultados estimados para a probabilidade de um indivíduo ser classificado como sobre-educado, de acordo com o modelo na equação (1). Para os indivíduos com até o ensino médio completo, a coluna (1) mostra que os egressos de instituições públicas apresentam probabilidade maior em 9,1 pontos percentuais de serem sobre-educados, quando comparados aos egressos de instituições privadas. Já quando a amostra considera apenas indivíduos com pelo menos um ano completo em um curso superior, na coluna (2), a probabilidade de um trabalhador vindo da rede pública ser classificado 
como sobre-educado é menor em 2,7 pontos percentuais em relação a um trabalhador vindo de uma instituição privada.

Na coluna (3) da Tabela 3, os resultados são restritos aos indivíduos com exatamente o ensino médio completo. Nesse caso, a probabilidade de sobreeducação para os que completaram esse curso em uma instituição pública é maior em 14,2 pontos percentuais. Para os indivíduos com exatamente o curso superior completo, a coluna (4) mostra que a probabilidade de sobre-educação é menor em 4,5 pontos percentuais para os que completaram esse curso em uma instituição da rede pública.

As evidências na Tabela 3 estão de acordo com o argumento de que a pior qualidade das instituições públicas de ensino básico aumenta a propensão para que os indivíduos que frequentaram esse tipo de instituição tenham uma ocupação que exige escolaridade menor que a obtida em relação aos trabalhadores com a mesma escolaridade, mas que frequentaram o curso mais elevado na rede privada. Situação inversa é observada no caso do ensino superior, no qual a rede pública é considerada de melhor qualidade. Nota-se também que as diferenças entre os tipos de instituição são mais acentuadas no caso do ensino médio. Além disso, as comparações entre as colunas (1) e (3) e entre (2) e (4) mostram que os diferenciais são maiores, em ambos os casos, para os que possuem graus completos de estudos.

A Tabela 3 mostra ainda que a probabilidade de sobre-educação é menor para as mulheres e maior para os negros, controlando para as variáveis incluídas na regressão. Para os indivíduos com até o ensino médio, cada ano adicional de estudo aumenta a probabilidade de ter uma ocupação com menor necessidade educacional. A relação entre escolaridade e sobre-educação, porém, é negativa para os indivíduos com algum ano completo de educação superior. Ou seja, a conclusão do curso superior reduz a probabilidade de o trabalhador ter um emprego onde é considerado sobre-educado em relação a trabalhadores que cursaram uma faculdade, mas sem completar, que acabam ficando restritos a ocupações com exigência de ensino médio ou menos. A idade apresenta uma relação decrescente com a probabilidade de sobreeducação, ou seja, a propensão à sobre-educação é maior para os jovens, com reduções na probabilidade ocorrendo a taxas cada vez menores à medida que a idade aumenta.

\subsection{Resultados considerando a seleção amostral}

Nesta subseção, são apresentados os resultados que consideram o fato de que indivíduos desempregados e inativos não podem ser classificados em relação a sobre-educação, já que não possuem uma ocupação. A própria probabilidade de estar empregado, por sua vez, pode depender da rede de ensino que o indivíduo frequentou. Para considerar essa questão, a Tabela 4 mostra os resultados obtidos para um modelo probit com seleção amostral, como descrito na seção $5:^{12}$

As estimativas para os indivíduos com até o ensino médio mostram coeficientes positivos e significativos para a dummy de egressos de instituições públicas, mas que são ligeiramente menores que os reportados na Tabela 3. Embora isso sugira que a seleção dos indivíduos com até o ensino médio que

\footnotetext{
${ }^{12}$ Os resultados estimados para a equação de seleção são mostrados no Apêndice, na Tabela A.1.
} 
Tabela 3: Probabilidade de sobre-educação e rede de ensino efeitos marginais.

\begin{tabular}{|c|c|c|}
\hline & $(1)$ & $(2)$ \\
\hline & $\begin{array}{l}\text { Escolaridade: } 11 \\
\text { anos ou menos }\end{array}$ & $\begin{array}{c}\text { Escolaridade: } 12 \\
\text { anos ou mais }\end{array}$ \\
\hline Instituição pública & $\begin{array}{l}0,091 \\
{[0,008]^{* * *}}\end{array}$ & $\begin{array}{l}-0,027 \\
{[0,009]^{* * *}}\end{array}$ \\
\hline Escolaridade & $\begin{array}{l}0,06 \\
{[0,008]^{* * *}}\end{array}$ & $\begin{array}{l}-0,15 \\
{[0,005]^{* * *}}\end{array}$ \\
\hline Idade & $\begin{array}{l}-0,002 \\
{[0,002]}\end{array}$ & $\begin{array}{l}-0,018 \\
{[0,004]^{* * *}}\end{array}$ \\
\hline Idade ao quadrado & $\begin{array}{r}0,0001 \\
{[0,000]}\end{array}$ & $\begin{array}{l}0,0001 \\
{[0,000]^{* * *}}\end{array}$ \\
\hline Mulher & $\begin{array}{l}-0,128 \\
{[0,004]^{* * *}}\end{array}$ & $\begin{array}{l}-0,08 \\
{[0,009]^{* * *}}\end{array}$ \\
\hline Negro & $\begin{array}{l}0,034 \\
{[0,005]^{* * *}}\end{array}$ & $\begin{array}{l}0,055 \\
{[0,010]^{* * *}}\end{array}$ \\
\hline Observações & 92,928 & 27,973 \\
\hline & (3) & (4) \\
\hline & $\begin{array}{c}\text { Ensino médio } \\
\text { Completo (11 anos) }\end{array}$ & $\begin{array}{c}\text { Ensino superior } \\
\text { Completo (15 anos) }\end{array}$ \\
\hline Instituição pública & $\begin{array}{l}0,142 \\
{[0,013]^{* * *}}\end{array}$ & $\begin{array}{l}-0,045 \\
{[0,009]^{* * *}}\end{array}$ \\
\hline Escolaridade & & \\
\hline Idade & $\begin{array}{c}0,005 \\
{[0,004]}\end{array}$ & $\begin{array}{l}-0,018 \\
{[0,004]^{* * *}}\end{array}$ \\
\hline Idade ao quadrado & $\begin{array}{r}0,0001 \\
{[0,000]}\end{array}$ & $\begin{array}{c}0,0001 \\
{[0,000]^{* * *}}\end{array}$ \\
\hline Mulher & $\begin{array}{l}-0,161 \\
{[0,007]^{* * *}}\end{array}$ & $\begin{array}{l}-0,061 \\
{[0,010]^{* * *}}\end{array}$ \\
\hline Negro & $\begin{array}{l}0,064 \\
{[0,008]^{* * *}}\end{array}$ & $\begin{array}{l}0,044 \\
{[0,011]^{* * *}}\end{array}$ \\
\hline Observações & 36,264 & 20,451 \\
\hline \multicolumn{3}{|c|}{$\begin{array}{l}\text { Nota: Regressões estimadas usando um modelo probit. Todas as } \\
\text { regressões incluem dummies para região de residência. Os erros-padrão } \\
\text { são mostrados entre colchetes. } \\
\text { * Significativo para o nível de } 10 \% \\
{ }^{* *} \text { Significativo para o nível de } 5 \% \\
* \text { Significativo para o nível de } 1 \%\end{array}$} \\
\hline
\end{tabular}


Tabela 4: Probabilidade de sobre-educação com correção para viés de seleção

\begin{tabular}{lc|c}
\hline & $(\mathbf{1})$ & $(2)$ \\
\cline { 2 - 3 } & $\begin{array}{c}\text { Escolaridade } \\
\mathbf{1 1} \text { anos } \\
\text { ou menos }\end{array}$ & $\begin{array}{c}\text { Escolaridade } \\
\mathbf{1 2} \text { anos } \\
\text { ou mais }\end{array}$ \\
\hline Instituição pública & 0,086 & $-0,028$ \\
& {$[0,011]^{* * *}$} & {$[0,009]^{* * *}$} \\
Escolaridade & 0,059 & $-0,153$ \\
Idade & {$[0,004]^{* * *}$} & {$[0,007]^{* * *}$} \\
& $-0,004$ & $-0,02$ \\
Idade ao quadrado & {$[0,004]$} & {$[0,006]^{* * *}$} \\
& 0,0001 & 0,0002 \\
Mulher & {$[0,000]$} & {$[0,000]^{* * *}$} \\
Negro & $-0,112$ & $-0,077$ \\
& {$[0,014]^{* * *}$} & {$[0,012]^{* * *}$} \\
Parâmetro $\rho$ & 0,032 & 0,055 \\
& {$[0,006]^{* * *}$} & {$[0,010]^{* * *}$} \\
Teste de Wald p/ independência & $-0,119$ & $-0,065$ \\
entre as equações do modelo $(\rho=0)$ & 0,37 & {$[0,138]$} \\
& & 0,22 \\
\hline Observações & 150,505 & 34,711 \\
Observações censuradas & 57,577 & 6,738 \\
\hline
\end{tabular}

Nota: Regressões estimadas usando um modelo probit. Todas as regressões incluem dummies para região de residência. Na equação de seleção, são incluídas também as seguintes variáveis: número de crianças com 5 anos ou menos no domicício, e a interação dessa variável com a dummy Mulher.

Os erros-padrão são mostrados entre colchetes

conseguem emprego contribua para aumentar o diferencial entre as redes de ensino, o parâmetro $\rho$ não é estatisticamente diferente de zero. Os resultados também mostram que a hipótese de independência entre a equação para a probabilidade de sobre-educação e a equação de seleção não é rejeitada nem na coluna (1) nem na (3). Portanto, não são encontradas evidências de que a seleção entre os ocupados influencie os resultados.

Entre os indivíduos com algum ano de educação superior, os coeficientes com correção para o viés de seleção são muito semelhantes aos mostrados anteriormente na Tabela 3. Também nesse caso, não são encontradas evidências de viés de seleção entre os indivíduos ocupados, como se observa pelo parâmetro $\rho$ e pelo resultado do teste de Wald. Esses resultados para os trabalhadores com formação superior não chegam a surpreender, já que a taxa de ocupação nesse grupo é bastante elevada.

\subsection{Resultados considerando a possibilidade de subeducação}

A análise mostrada na Tabela 5 consiste em estimar a relação entre o tipo da rede de ensino frequentada pelo indivíduo e a sua condição no mercado de trabalho considerando três alternativas: subeducado, adequadamente educado e 
Tabela 4: Probabilidade de sobre-educação com correção para viés de seleção (continuação)

\begin{tabular}{|c|c|c|}
\hline & (3) & (4) \\
\hline & $\begin{array}{c}\text { Ensino médio } \\
\text { Completo } \\
\text { (11 anos) }\end{array}$ & $\begin{array}{c}\text { Ensino superior } \\
\text { Completo } \\
(15 \text { anos })\end{array}$ \\
\hline Instituição pública & $\begin{array}{l}0,12 \\
{[0,020]^{* * *}}\end{array}$ & $\begin{array}{l}-0,044 \\
{[0,011]^{* * *}}\end{array}$ \\
\hline \multicolumn{3}{|l|}{ Escolaridade } \\
\hline Idade & $\begin{array}{l}0,016 \\
{[0,007]^{* *}}\end{array}$ & $\begin{array}{r}-0,017 \\
{[0,011]}\end{array}$ \\
\hline Idade ao quadrado & $\begin{array}{l}-0,0002 \\
{[0,000]^{* *}}\end{array}$ & $\begin{array}{r}0,0002 \\
{[0,000]}\end{array}$ \\
\hline Mulher & $\begin{array}{l}-0,203 \\
{[0,017]^{* * *}}\end{array}$ & $\begin{array}{l}-0,062 \\
{[0,017]^{* * *}}\end{array}$ \\
\hline Negro & {$[0,012]^{* * *}$} & $\begin{array}{l}0,043 \\
{[0,012]^{* * *}}\end{array}$ \\
\hline Parâmetro $\rho$ & $\begin{array}{c}0,621 \\
{[0,516]}\end{array}$ & $\begin{array}{c}0,018 \\
{[0,369]}\end{array}$ \\
\hline $\begin{array}{l}\text { Teste de Wald } \mathrm{p} / \text { independência } \\
\text { entre as equações do modelo }(\rho=0)\end{array}$ & 1,45 & 0,00 \\
\hline Observações & 51,712 & 24,554 \\
\hline Observações censuradas & 15,448 & 4,103 \\
\hline
\end{tabular}

sobre-educado. Essa análise é baseada no modelo logit multinomial descrito na seção 5 .

Nas colunas (1) e (2), a probabilidade de subeducação em relação a ter uma ocupação correspondente com a escolaridade é menor para os egressos da rede pública, considerada de pior qualidade para o ensino básico, em média. Quando a dummy para instituição pública é um, a razão entre a probabilidade de um trabalhador ter uma ocupação que exige mais anos de escolaridade do que ele de fato alcançou e a probabilidade de ter uma ocupação adequada para a escolaridade (grupo base) é igual a 0,583. Já para os sobre-educados, o resultado é inverso. Pela coluna (2), sendo a dummy para instituição pública igual a um, a razão entre a probabilidade de sobre-educação e a probabilidade de pertencer ao grupo base é 1,642.

Os resultados são muito parecidos nas colunas (3) e (4) quando a amostra é restrita àqueles com exatamente o ensino médio completo. Além de reforçar os resultados anteriores, as estimativas na Tabela 5 sugerem que para trabalhadores com o mesmo nível educacional, os egressos da rede com melhor qualidade média apresentam uma probabilidade maior de desempenhar atividades mais complexas que as compatíveis com os anos de escolaridade que completaram do que de pertencer ao grupo base, quando comparados aos 
egressos da rede com pior qualidade média.

Tabela 5: Tipo de instituição de ensino e desajuste educacional (trabalhadores com até o ensino médio) - modelo logit multinomial

\begin{tabular}{lcc}
\hline & \multicolumn{1}{c}{$(\mathbf{1})$} & $(2)$ \\
\cline { 2 - 3 } & \multicolumn{2}{c}{ Escolaridade: 11 anos ou men } \\
\cline { 2 - 3 } & Coeficiente & $\begin{array}{r}\text { Razão de } \\
\text { risco relat }\end{array}$ \\
\hline 1) Subeducado & & \\
& & \\
Instituição pública & $-0,54$ & 0,583 \\
Escolaridade & {$[0,076]^{* * *}$} & \\
Idade & $-0,465$ & 0,628 \\
& {$[0,005]^{* * *}$} & \\
Idade ao quadrado & 0,083 & 1,086 \\
Mulher & {$[0,013]^{* * *}$} & \\
Negro & $-0,001$ & 0,999 \\
& {$[0,0002]^{* * *}$} & \\
Constante & $-0,001$ & 0,999 \\
& {$[0,028]$} & 0,975 \\
& $-0,026$ & \\
& {$[0,030]$} & 5,257 \\
& 1,66 & \\
\end{tabular}

\begin{tabular}{|c|c|c|}
\hline 2)Adequadamente escolarizado & & Grupo de referência \\
\hline \multicolumn{3}{|l|}{ 3) Sobre-educado } \\
\hline Instituição pública & $\begin{array}{l}0,496 \\
{[0,064]^{* * *}}\end{array}$ & 1,642 \\
\hline Escolaridade & $\begin{array}{l}0,187 \\
{[0,006]^{* * *}}\end{array}$ & 1,206 \\
\hline Idade & $\begin{array}{c}0,007 \\
{[0,012]}\end{array}$ & 1,007 \\
\hline Idade ao quadrado & $\begin{array}{c}0,000 \\
{[0,0001]}\end{array}$ & 1,000 \\
\hline Mulher & $\begin{array}{l}-0,747 \\
{[0,026]^{* * *}}\end{array}$ & 0,474 \\
\hline Negro & $\begin{array}{l}0,191 \\
{[0,028]^{* * *}}\end{array}$ & 1,211 \\
\hline Constante & $\begin{array}{l}-2,334 \\
{[0,249]^{* * *}}\end{array}$ & 0,097 \\
\hline Observações & 92,928 & \\
\hline
\end{tabular}

\subsection{Resultados adicionais}

São apresentadas agora algumas análises adicionais de robustez. Espera-se que a qualidade da educação formal adquirida seja, em média, mais impor- 
Tabela 5: Tipo de instituição de ensino e desajuste educacional (trabalhadores com até o ensino médio) - modelo logit multinomial (continuação)

\begin{tabular}{|c|c|c|}
\hline & (3) & (4) \\
\hline & \multicolumn{2}{|c|}{ Apenas ensino médio Completo (11 anos) } \\
\hline & $\begin{array}{c}\text { Coeficiente } \\
\text { [Erro padrão] }\end{array}$ & $\begin{array}{c}\text { Razão de } \\
\text { risco relativo }\end{array}$ \\
\hline \multicolumn{3}{|l|}{ 1) Subeducado } \\
\hline Instituição pública & $\begin{array}{l}-0,483 \\
{[0,087]^{* * *}}\end{array}$ & 0,617 \\
\hline Escolaridade & - & \\
\hline Idade & $\begin{array}{l}0,093 \\
{[0,027]^{* * *}}\end{array}$ & 1,098 \\
\hline Idade ao quadrado & $\begin{array}{l}-0,001 \\
{[0,0003]^{* *}}\end{array}$ & 0,999 \\
\hline Mulher & $\begin{array}{l}-0,399 \\
{[0,063]^{* * *}}\end{array}$ & 0,671 \\
\hline Negro & $\begin{array}{l}-0,29 \\
{[0,066]^{* * *}}\end{array}$ & 0,748 \\
\hline Constante & $\begin{array}{l}-3,369 \\
{[0,556]^{* * *}}\end{array}$ & 0,034 \\
\hline 2) Adequadamente escolarizado & & Grupo de referência \\
\hline \multicolumn{3}{|l|}{ 3) Sobre-educado } \\
\hline Instituição pública & $\begin{array}{l}0,552 \\
{[0,068]^{* * *}}\end{array}$ & 1,736 \\
\hline Escolaridade & - & \\
\hline Idade & $\begin{array}{l}0,03 \\
{[0,015]^{* *}}\end{array}$ & 1,030 \\
\hline Idade ao quadrado & $\begin{array}{c}0,000 \\
{[0,0002]^{*}}\end{array}$ & 1,000 \\
\hline Mulher & $\begin{array}{l}-0,722 \\
{[0,032]^{* * *}}\end{array}$ & 0,486 \\
\hline Negro & $\begin{array}{l}0,232 \\
{[0,036]^{* * *}}\end{array}$ & 1,261 \\
\hline Constante & $\begin{array}{l}-1,09 \\
{[0,304]^{* * *}}\end{array}$ & 0,336 \\
\hline Observações & 36,264 & \\
\hline
\end{tabular}


tante para a inserção dos jovens no mercado de trabalho do que para os trabalhadores mais velhos. Com o acúmulo de capital humano pela experiência no mercado de trabalho, a qualidade da instituição de ensino deve ter a sua influência cada vez mais reduzida.

Tabela 6: Probabilidade de sobre-educação por idade (trabalhadores com ensino médio completo) - efeitos marginais

\begin{tabular}{|c|c|c|c|}
\hline & (1) & (2) & (3) \\
\hline & $\begin{array}{c}\text { Idade: } \\
\text { 25-34 anos }\end{array}$ & $\begin{array}{c}\text { Idade: } \\
\text { 35-44 anos }\end{array}$ & $\begin{array}{c}\text { Idade: } \\
45-60 \text { anos }\end{array}$ \\
\hline Instituição pública & $\begin{array}{l}0,191 \\
{[0,023]^{* * *}}\end{array}$ & $\begin{array}{l}0,142 \\
{[0,023]^{* * *}}\end{array}$ & $\begin{array}{l}0,096 \\
{[0,023]^{* * *}}\end{array}$ \\
\hline Idade & $\begin{array}{l}-0,004 \\
{[0,050]}\end{array}$ & $\begin{array}{l}-0,111 \\
{[0,074]}\end{array}$ & $\begin{array}{l}-0,061 \\
{[0,039]}\end{array}$ \\
\hline Idade ao quadrado & $\begin{array}{c}0,001 \\
{[0,001]}\end{array}$ & $\begin{array}{c}0,001 \\
{[0,001]}\end{array}$ & $\begin{array}{c}0,001 \\
{[0,001]}\end{array}$ \\
\hline Mulher & $\begin{array}{l}-0,222 \\
{[0,012]^{* * *}}\end{array}$ & $\begin{array}{l}-0,15 \\
{[0,013]^{* * *}}\end{array}$ & $\begin{array}{l}-0,086 \\
{[0,013]^{* * *}}\end{array}$ \\
\hline Negro & $\begin{array}{l}0,045 \\
{[0,014]^{* * *}}\end{array}$ & $\begin{array}{l}0,065 \\
{[0,015]^{* * *}}\end{array}$ & $\begin{array}{l}0,097 \\
{[0,014]^{* * *}}\end{array}$ \\
\hline Observações & 14,726 & 11,627 & 9,911 \\
\hline
\end{tabular}

Na Tabela 6, são mostrados os resultados estimados para a probabilidade de sobre-educação entre indivíduos com exatamente o ensino médio completo para três diferentes faixas etárias. Percebe-se que a maior probabilidade de sobre-educação associada com a rede pública tem um grau ainda mais acentuado para os mais jovens. Nessa faixa etária, os egressos da rede pública apresentam uma probabilidade de sobre-educação 19,1 pontos percentuais maior que os egressos da rede privada. Já na faixa de idade entre 45 e 60 anos, a diferença é estimada em 9,6 pontos percentuais.

Na Tabela 7, a análise por grupo etário é realizada para a amostra de indivíduos com ensino superior completo. Nesse caso, o diferencial passa a ser favorável às instituições públicas, no sentido de apresentarem menor probabilidade de sobre-educação. Esse diferencial é ampliado com o aumento da idade, embora as diferenças entre os grupos etários sejam pequenas. Entre os jovens, a probabilidade de sobre-educação é 3,5 pontos percentuais menor para os que saíram de instituições públicas, enquanto entre os indivíduos com idade entre 45 e 60 anos esse diferencial é estimado em 5 pontos percentuais.

Os resultados mostram, portanto, que para os trabalhadores com até o ensino médio completo, o tipo de instituição parece bastante importante nos primeiros anos no mercado de trabalho. Com a experiência no emprego e o acúmulo de capital humano, o fato de ter cursado uma instituição da rede pública deixa de ser tão importante, apesar do diferencial em relação à rede privada permanecer. O mesmo, porém, não se observa para os indivíduos com formação superior, não sendo condizente, nesse caso, com o resultado previsto pelo argumento proposto nesse artigo e para a hipótese adotada para o papel da qualidade da instituição de ensino ao longo tempo no mercado de trabalho. 
Tabela 7: Probabilidade de sobre-educação por idade (trabalhadores com ensino superior completo) - efeitos marginais.

\begin{tabular}{l|c|c|c}
\hline \multirow{2}{*}{ Instituição pública } & $(\mathbf{1})$ & $(2)$ & $(\mathbf{3})$ \\
\cline { 2 - 4 } & Idade: & Idade: & Idade: \\
& 25-34 anos & 35-44 anos & 45-60 anos \\
\hline \multirow{4}{*}{ Idade } & $-0,035$ & $-0,047$ & $-0,050$ \\
Idade ao quadrado & {$[0.017]^{* *}$} & {$[0.015]^{* * *}$} & {$[0.015]^{* * *}$} \\
& 0,015 & $-0,099$ & $-0,016$ \\
Mulher & {$[0.071]$} & {$[0.083]$} & {$[0.043]$} \\
& 0,001 & 0,001 & 0,001 \\
Negro & {$[0.001]$} & {$[0.001]$} & {$[0.001]$} \\
& $-0,068$ & $-0,069$ & $-0,041$ \\
& {$[0.018]^{* * *}$} & {$[0.015]^{* * *}$} & {$[0.015]^{* * *}$} \\
& 0,04 & 0,063 & 0,027 \\
Observações & {$[0.020]^{* *}$} & {$[0.018]^{* * *}$} & {$[0.017]^{* * *}$} \\
\hline \multicolumn{3}{l|}{ Nota: Regressões estimadas usando um modelo probit. Todas as } \\
regressões incluem dummies para região de residência. Os erros-padrão \\
são mostrados entre colchetes.
\end{tabular}

Apesar dos resultados apresentados nesta seção indicarem uma associação negativa entre a qualidade média da rede de ensino e a probabilidade de sobre-educação, deve-se ter cautela em relação a interpretações de causalidade. Além da qualidade do ensino, outros fatores devem ser importantes. No ensino básico, os indivíduos alocados nas escolas públicas também costumam ter pais menos escolarizados e renda domiciliar mais baixa. Essa estrutura familiar pode influenciar o desempenho desses indivíduos no mercado de trabalho de outras formas, além da educação formal adquirida. Com isso, o efeito atribuído à qualidade do ensino seria, na verdade, devido à estrutura familiar. Deve-se mencionar também o fato de os indivíduos com até o ensino médio terem, muito possivelmente, características bem distintas daqueles que cursaram o ensino superior. Esse fator deve ser particularmente importante para os egressos de escolas privadas, que representam uma proporção bem pequena dos que alcançaram, no máximo, esse nível educacional. Apesar de provavelmente possuírem condições econômicas e sociais mais favoráveis, esses indivíduos não alcançaram a educação superior.

No caso da educação superior, a influência da estrutura familiar também deve estar presente. Além disso, o processo de admissão nas universidades públicas costuma ser muito concorrido, levando a uma seleção das pessoas mais produtivas na rede pública em detrimento das instituições privadas, onde as exigências para o ingresso, e até para a conclusão dos cursos, são normalmente bem menores. Com isso, pelo menos uma parte do efeito atribuído à rede de ensino seria, na verdade, resultado da qualidade dos alunos. Para tentar pelo menos minimizar a influência da estrutura familiar nos resultados e reduzir as disparidades nas condições de acesso ao ensino superior, a Tabela 8 apresenta estimativas para a probabilidade de sobre-educação entre indivíduos que concluíram o curso superior condicionando no tipo de instituição de ensino onde concluíram o ensino médio.

Entre os que concluíram o ensino médio em escolas privadas, existe uma grande heterogeneidade em relação à estrutura familiar, mas que deve ser 
Tabela 8: Probabilidade de sobre-educação condicionando no tipo de instituição de ensino médio

\begin{tabular}{lcc}
\hline & \multicolumn{1}{c}{$(\mathbf{1})$} & $(2)$ \\
\cline { 2 - 3 } & Ensino superior completo (15 anos) \\
\cline { 2 - 3 } & $\begin{array}{c}\text { Ensino médio em } \\
\text { escola privada }\end{array}$ & $\begin{array}{c}\text { Ensino médio em } \\
\text { escola pública }\end{array}$ \\
\hline Instituição pública & $-0,058$ & $-0,052$ \\
Idade & {$[0,014]^{* * *}$} & {$[0,012]^{* * *}$} \\
Idade ao quadrado & $-0,018$ & $-0,019$ \\
& {$[0,006]^{* * *}$} & {$[0,006]^{* * *}$} \\
Mulher & 0,0001 & 0,0001 \\
& {$[0,000]^{* * *}$} & {$[0,000]^{* *}$} \\
Negro & $-0,039$ & $-0,081$ \\
& {$[0,014]^{* * *}$} & {$[0,013]^{* * *}$} \\
& 0,044 & 0,016 \\
& {$[0,017]^{* * *}$} & {$[0,015]$} \\
\hline Observações & 6377 & 13259 \\
\hline Nota: Regressões estimadas usando um modelo probit. Todas as \\
regressões incluem dummies para região de residência. Os \\
erros-padrão são mostrados entre colchetes. \\
* Significativo para o nível de $10 \%$ \\
** Significativo para o nível de $5 \%$ \\
*** Significativo para o nível de $1 \%$ \\
\end{tabular}

bem menor que a encontrada na amostra utilizada na coluna (4) da Tabela 3. O mesmo deve ser válido condicionando a análise aos que concluíram o ensino médio em escolas públicas. Para o primeiro grupo, a coluna (1) da Tabela 8 mostra que a probabilidade de sobre-educação é 5,8 pontos percentuais menor para os egressos de instituições públicas de nível superior. Para os que concluíram o ensino médio em instituições públicas, a coluna (2) mostra que esse diferencial é estimado em 5,2 pontos percentuais. Os resultados não são muito diferentes dos reportados na coluna (4) da Tabela 3, sem condicionar no tipo de instituição de ensino médio, que indicam uma probabilidade de sobre-educação menor em 4,5 pontos percentuais para os que concluíram o ensino superior em instituições públicas. Note que, na análise mostrada na Tabela 8, as características produtivas não observadas devem ser distintas entre os que ingressam em instituições públicas e privadas, o que também pode influenciar a probabilidade de sobre-educação.

\section{Conclusão}

Trabalhadores em empregos com escolaridade mais elevada que a considerada necessária nas suas ocupações costumam receber rendimentos menores do que receberiam caso conseguissem uma ocupação compatível com o nível de escolaridade que alcançaram. A sobre-educação também pode ter consequências negativas para o nível de satisfação no emprego e para a produtividade, representando custos importantes para os trabalhadores e para as firmas. Esse artigo procurou analisar em que medida frequentar uma instituição pública ou privada de ensino no Brasil pode ser um determinante para a probabilidade de sobre-educação. 
Os resultados estimados são consistentes com a hipótese de que deficiências na aquisição de capital humano com a educação formal levam os trabalhadores a necessitarem de mais anos de estudos para adquirir determinada qualificação do que precisariam caso a qualidade da educação fosse adequada. Entre os indivíduos com o ensino médio completo, os egressos de escolas da rede pública têm maior probabilidade de serem sobre-educados do que os que saíram de escolas privadas, que apresentam, em média, melhor qualidade de ensino nesse nível de educação. Situação inversa é observada para os indivíduos com curso superior.

É importante ressaltar que outros fatores podem estar influenciando os resultados da análise, como as características individuais dos trabalhadores e as diferenças na estrutura familiar. No entanto, seja pela qualidade do ensino ou por outros fatores correlacionados, os resultados sugerem que os egressos de instituições da rede pública de ensino básico e a da rede privada de ensino superior não parecem, em média, capacitados para exercer as atividades compatíveis com o número de anos de estudo que completaram. Com isso, acabam se tornando mais propensos a se empregarem em ocupações nas quais as exigências são menores. No caso das instituições públicas de nível básico, é importante melhorar a capacitação dos alunos, procurando compensar as deficiências em relação aos alunos da rede privada, para que tenham igualdade de condições no acesso ao nível superior e no próprio ingresso no mercado de trabalho. Em relação ao ensino superior, a participação das instituições privadas tem se expandido rapidamente. É importante, porém, que a qualidade da formação educacional oferecida também avance para que uma proporção maior de trabalhadores possa desempenhar atividades compatíveis com o nível de escolaridade que alcançaram.

\section{Referências Bibliográficas}

Allen, J. \& Van der Velden, R. (2001). Educational mismatches versus skill mismatches: effects on wages, job satisfaction, and on-the-job search. Oxford economic papers, Oxford University Press, v. 53, n. 3, p. 434-452.

Bauer, T. K. (2002). Educational mismatch and wages: a panel analysis. Economics of education review, Elsevier, v. 21, n. 3, p. 221-229.

Classificação Brasileira de Ocupações - CBO (2010). Ministério do Trabalho e do Emprego. 3. ed. Brasília.

Diaz, M. D. M. \& M, L. (2008). Overeducation e undereducation no Brasil: incidência e retornos. Estudos Econômicos (São Paulo), SciELO Brasil, v. 38, n. 3, p. 431-460.

Groot, W. \& Van Den Brink, H. M. (2000). Overeducation in the labor market: a meta-analysis. Economics of education review, Elsevier, v. 19, n. 2, p. 149158.

Hartog, J. (2000). Over-education and earnings: where are we, where should we go? Economics of education review, Elsevier, v. 19, n. 2, p. 131-147.

Heckman, J. (1979). Sample selection error as a specification bias. Econometrica, v. 47, n. 1, p. 153-161. 
INEP (2011). SAEB/Prova Brasil 2011 - primeiros resultados. INEP, Ministério da Educação.

Korpi, T. \& Tåhlin, M. (2009). Educational mismatch, wages, and wage growth: Overeducation in Sweden, 1974-2000. Labour Economics, Elsevier, v. 16 , n. 2, p. 183-193.

Leuven, E. \& Oosterbeek, H. (2011). Handbook of the Economics of Education. In: Overeducation and mismatch in the labor market. 4. ed. Elsevier, p. 283-326.

Marioni, L. S. (2018). Overeducation in the labour market: Evidence from Brazil. Royal Economic Society Annual Conference, University of Sussex, Brighton, United Kingdom.

McGuinness, S. (2006). Overeducation in the labour market. Journal of economic surveys, Wiley Online Library, v. 20, n. 3, p. 387-418.

Mehta, A., Felipe, J., Quising, P. \& Camingue, S. (2011). Overeducation in developing economies: How can we test for it, and what does it mean? Economics of Education Review, Elsevier, v. 30, n. 6, p. 1334-1347.

Organização para a Cooperação e Desenvolvimento Econômico - OCDE (2013). Assessing higher education learning outcomes in Brazil. Higher Education Management and Policy, v. 24, n. 2.

Pauli, R. C., Nakabashi, L. \& Sampaio, A. V. (2012). Mudança estrutural e mercado de trabalho no Brasil. Brazilian Journal of Political Economy, SciELO Brasil, v. 32, n. 3, p. 459-478.

Quintini, G. (2011). Over-qualified or under-skilled: A review of existing literature. OECD Publishing (OECD social, employment and migration. Working papers no. 121).

Reis, M. C. (2017). Educational mismatch and labor earnings in Brazil. International Journal of Manpower, Emerald Publishing Limited, v. 38, n. 2, p. 180-197.

Robst, J. (1995). College quality and overeducation. Economics of Education Review, Elsevier, v. 14, n. 3, p. 221-228.

Sattinger, M. (1993). Assignment models of the distribution of earnings. Journal of economic literature, JSTOR, v. 31, n. 2, p. 831-880.

Sicherman, N. (1991). "Overeducation"in the labor market. Journal of labor Economics, University of Chicago Press, v. 9, n. 2, p. 101-122.

Sloane, P. J. (2003). Much ado about nothing? What does the overeducation literature really tell us. Overeducation in Europe, Edward Elgar Northampton, MA, p. 11-45.

Spence, M. (1973). Job market signaling. Quarterly Journal of Economics, v. 87 , n. 3, p. 355-374.

Terra, R., Zoghbi, A. C. \& Felício, F. (2012). Produtividade relativa dos setores público e provado em educação: impactos sobre a escolha da escola pela família. Economia Aplicada, SciELO Brasil, v. 16, n. 4, p. 579-611. 
Thurow, L. C. (1975). Generating inequality. 2. ed. Local: Basic books.

Tsai, Y. (2010). Returns to overeducation: A longitudinal analysis of the US labor market. Economics of Education Review, Elsevier, v. 29, n. 4, p. 606-617.

Van de Ven, W. \& Van Pragg, B. (1981). The demand for deductibles in private health insurance: A probit model with sample selection. Journal of econometrics, North-Holland, v. 17, n. 2, p. 229-252.

Verhofstadt, E., De Witte, H. \& Omey, E. (2007). Higher educated workers: better jobs but less satisfied? International Journal of Manpower, Emerald Group Publishing Limited, v. 28, p. 135-151.

\section{Apêndice A}


Tabela A.1: Resultados do primeiro estágio para o modelo de probabilidade de sobre-educação com correção para viés de seleção (coeficientes)

\begin{tabular}{|c|c|c|}
\hline & (1) & (2) \\
\hline & $\begin{array}{c}\text { Escolaridade } \\
11 \text { anos } \\
\text { ou menos }\end{array}$ & $\begin{array}{c}\text { Escolaridade } \\
12 \text { anos } \\
\text { ou mais }\end{array}$ \\
\hline Instituição pública & $\begin{array}{c}0,048 \\
{[0,029]^{*}}\end{array}$ & $\begin{array}{l}0,059 \\
{[0,023]^{* *}}\end{array}$ \\
\hline Escolaridade & $\begin{array}{l}0,057 \\
{[0,001]^{* * *}}\end{array}$ & $\begin{array}{l}0,134 \\
{[0,011]^{* * *}}\end{array}$ \\
\hline Idade & $\begin{array}{l}0,134 \\
{[0,005]^{* * *}}\end{array}$ & $\begin{array}{l}0,190 \\
{[0,011]^{* * *}}\end{array}$ \\
\hline Idade ao quadrado & $\begin{array}{l}-0,002 \\
{[0,000]^{* * *}}\end{array}$ & $\begin{array}{l}-0,002 \\
{[0,000]^{* * *}}\end{array}$ \\
\hline Mulher & $\begin{array}{l}-0,840 \\
{[0,010]^{* * *}}\end{array}$ & $\begin{array}{l}-0,452 \\
{[0,026]^{* * *}}\end{array}$ \\
\hline Negro & $\begin{array}{l}-0,023 \\
{[0,011]^{* *}}\end{array}$ & $\begin{array}{l}-0,021 \\
{[0,027]}\end{array}$ \\
\hline $\begin{array}{l}\text { Número de crianças com } 5 \\
\text { anos ou menos no domicílio }\end{array}$ & $\begin{array}{l}0,137 \\
{[0,033]^{* * *}}\end{array}$ & $\begin{array}{l}0,356 \\
{[0,100]^{* * *}}\end{array}$ \\
\hline $\begin{array}{l}\text { Mulher x Número de crianças c/ } \\
5 \text { anos ou menos no domićlio }\end{array}$ & $\begin{array}{l}-0,283 \\
{[0,044]^{* * *}}\end{array}$ & 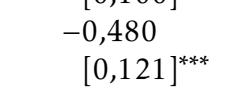 \\
\hline \multirow[t]{3}{*}{ Observações } & 150,505 & 34,711 \\
\hline & $(3)$ & $(4)$ \\
\hline & $\begin{array}{c}\text { Ensino médio } \\
\text { Completo } \\
\text { (11 anos) }\end{array}$ & $\begin{array}{c}\text { Ensino superior } \\
\text { Completo } \\
(15 \text { anos })\end{array}$ \\
\hline Instituição pública & $\begin{array}{c}0,053 \\
{[0,032]}\end{array}$ & $\begin{array}{l}0,08 \\
{[0,029]^{* * *}}\end{array}$ \\
\hline \multicolumn{3}{|l|}{ Escolaridade } \\
\hline Idade & $\begin{array}{l}0,123 \\
{[0,008]^{* * *}}\end{array}$ & $\begin{array}{l}0,202 \\
{[0,014]^{* * *}}\end{array}$ \\
\hline Idade ao quadrado & $\begin{array}{l}-0,002 \\
{[0,000]^{* * *}}\end{array}$ & $\begin{array}{l}-0,003 \\
{[0,000]^{* * *}}\end{array}$ \\
\hline Mulher & $\begin{array}{l}-0,717 \\
{[0,018]^{* * *}}\end{array}$ & $\begin{array}{l}-0,437 \\
{[0,032]^{* * *}}\end{array}$ \\
\hline Negro & $\begin{array}{l}-0,037 \\
{[0,019]^{*}}\end{array}$ & $\begin{array}{l}-0,023 \\
{[0,034]}\end{array}$ \\
\hline $\begin{array}{l}\text { Número de crianças com } 5 \\
\text { anos ou menos no domicílio }\end{array}$ & $\begin{array}{l}0,139 \\
{[0,061]^{* *}}\end{array}$ & $\begin{array}{l}0,264 \\
{[0,124]^{* *}}\end{array}$ \\
\hline $\begin{array}{l}\text { Mulher x Número de crianças c/ } \\
5 \text { anos ou menos no domicílio }\end{array}$ & $\begin{array}{l}-0,320 \\
{[0,075]^{* * *}}\end{array}$ & $\begin{array}{l}-0,330 \\
{[0,150]^{* *}}\end{array}$ \\
\hline Observações & 51,712 & 24,554 \\
\hline $\begin{array}{l}\text { Nota: Todas as regressões incluem } d \imath \\
\text { Os erros-padrão são mostrados entre } \\
* \text { Significativo para o nível de } 10 \% \\
{ }^{* *} \text { Significativo para o nível de } 5 \% \\
{ }^{* * *} \text { Significativo para o nível de } 1 \%\end{array}$ & $\begin{array}{l}\text { mies para região } \\
\text { lchetes. }\end{array}$ & esidência. \\
\hline
\end{tabular}


